\title{
An Action Research on Applying the ARCS Model and Stratified Teaching in an English Reading Class in a Chinese Elementary School
}

\author{
Gengchun Li, Huihui Yang, Jing Zhang \\ School of Foreign Languages, Taizhou University, Taizhou, P. R. China
}

\section{Email address:}

charlietjut@163.com (Gengchun Li)

\section{To cite this article:}

Gengchun Li, Huihui Yang, Jing Zhang. An Action Research on Applying the ARCS Model and Stratified Teaching in an English Reading Class in a Chinese Elementary School. International Journal of Applied Linguistics and Translation. Vol. 6, No. 1, 2020 , pp. $12-19$. doi: $10.11648 /$ j.ijalt.20200601.12

Received: January 21, 2020; Accepted: February 14, 2020; Published: February 24, 2020

\begin{abstract}
In a traditional English reading class, the process of imparting knowledge is insipid and learners' individual differences cannot be fully considered. It largely focuses on knowledge inculcation and teaching efficiency but widens the gaps of achievement among students of different levels to a certain extent. The ARCS model is comprised of attention, relevance, confidence and satisfaction, which works concertedly to improve students' interest and confidence in learning English, and stimulate and maintain students' intrinsic motivation. The Stratified Teaching Method can adapt to students' individual differences, through which individualized teaching can help students improve their reading abilities. In consideration of the respective advantages of the ARCS model and stratified teaching, this paper tries to put them into practice by integrating them into an English reading class. In the present study, the research methods of questionnaire survey, interview and case analysis are employed, and it is found that most of the respondents in the survey take a liking to learning English, but about half of them are driven by some kind of external motivation and lack confidence in learning English well. However, it is also found that most of them would harvest greater confidence after answering teacher's questions correctly, or performing well in class, or accomplishing their homework satisfactorily after class. It is therefore both necessary and important for teachers to implement the ARCS model of motivation and the Stratified Teaching Method in instructional design in order to enhance students' confidence and motivation in learning to read and allow every and each of them benefit from the reading class. This paper concludes with a specific example of a teaching plan based on the ARCS Model and Stratified Teaching Method.
\end{abstract}

Keywords: ARCS Model, Stratified Teaching, Reading Class, Elementary School

\section{The ARCS Model}

\subsection{Background to and Research on the ARCS Model}

The ARCS model was first put forward by John M. Keller in 1983. It is comprised of four elements, i.e. attention, relevance, confidence, and satisfaction and these interact with one another to motivate students to learn. The model was developed more than three decades ago, thus it is not surprising that it has been used in widely different contexts (e.g. in classrooms as well as in online environment) by researchers from different countries.

Most of the studies find that the ARCS model of motivation proves effective in enhancing the motivation to learn. For example, Keller applied the model to in-service teacher education programs and the results showed that the model was effective for teachers to improve students' motivation [1]. He proposed some strategies of motivational design in teaching and perfected the application of the ARCS model in instructional design [2]. He also studied how to apply this model to computer-aided teaching and distance education [3]. Dick and Carey integrated the ARCS model with Gagne's Nine-step Teaching Approach, which initiated the application of this model to the field of teaching in a real sense [4]. A study has been done by Keller and Suzuki on E-learning by using the ARCS model, which confirmed the validity of this model for the systematic design of motivationally enhanced instruction in E-learning; besides, 
systematic motivational design was shown to be effective when used properly and within the boundaries of changeable influences on learners [5]. Namura and colleagues found that the ARCS model is a very useful model for teachers to analyze their classes, and that motivational strategies that match the students and the learning context can be employed to enhance the students' motivation [6]. Ghbari examined the effect of the ARCS model on the achievement motivation and academic achievement of tenth grade students and found that the ARCS model could motivate students for advanced steps to learning and help to improve their academic achievement [7]. More recently, Li and Keller reviewed empirical research on applying the ARCS model to real educational settings, and from this review it can be seen that this model has been implemented in various countries and in different educational settings [8].

In China, some researchers try to borrow John Keller's theories about the ARCS model of motivation and explore how to adapt the model to specific situations of foreign language learning in Chinese contexts. For example, Liu applied the model to foreign language teaching assisted by multimedia network technology, to explore ways of cultivating and enhancing students' motivation, in the hope of strengthening autonomous learning of foreign language outside of classroom [9]. Chen proposed ten specific steps to localizing the model in elementary and middle schools in China in an attempt to promote teaching reform in these schools by combining Chinese and foreign teaching research [10]. Yu and Wang divided foreign language teaching into three related stages and constructed a pyramidal rank structure of foreign language teaching motivational design based on the ARCS model [11]. Lin carried out research in college English classroom using the ARCS model of motivation, whose findings showed that students' motivation in English learning has been stimulated to some extent, and that the four aspects of this model have influenced students' motivation in different ways [12]. Shen integrated the ARCS model of motivation into spoken English instruction, and found that the ARCS model has greatly stimulated students' motivation in oral English learning [13].

Through a check of the literature home and abroad, the author found that there are a variety of studies pertinent to the ARCS model in different fields, such as education, teacher training, courseware design, multi-media teaching, etc. With respect to studies of the ARCS model in education, higher education accounts for a large proportion, but there are few studies of this model in primary and secondary education. Most studies focus on applying the model to teaching design, especially English teaching design, which takes up a large proportion in that English teaching attaches more importance to motivational design compared to other subjects. Moreover, there are few studies that connect the model with the Stratified Teaching Method.

\subsection{Analysis of the ARCS Model}

Essentially, the ARCS model can be summarized as four steps. The first step is to draw people's attention and arouse their interest in certain things. The next step is to make them realize their relevance with these things. The third step is to help them build confidence. The final step is to let them experience a sense of satisfaction from the whole process and its positive results.

\subsubsection{Attention}

According to Keller, there are three main approaches to attracting attention [14].

1) Perceptual Arousal

Learners are always interested in something new and/or unexpected. Therefore, using novel and individualized materials can draw learners' attention. The other strategy is to externalize the abstraction, which means to use content-related examples for illustration.

2) Inquiry Arousal

Learners can be motivated to explore and think by being posed some questions and presented with something implausible or contradictory. Building in problem-solving activities in which everyone is involved is also helpful.

3) Variability

Learners' attention can be affected by several factors, such as novelty, speed, variability, and comparison, etc. It is necessary for the teacher to change traditional format of teaching and infuse something new. The teacher can also change his/her body language, vary the tone of voice, and/or use body movement, pauses, and props.

\subsubsection{Relevance}

Learners' interest and motivation to learn will be stimulated after realizing that the new knowledge is relevant to them. Relevance can be divided into two types: goal relevance and process relevance. With respect to goal relevance, learners would be greatly motivated to learn when the contents of learning can help them accomplish objectives in their life. The two categories of strategy to realize process relevance include "motive matching" and "familiarity".

The strategy to realize "goal relevance" is to help learners set their own learning objectives and present them with the value and utility of the learning contents.

To realize "motive matching", teachers can offer learners various learning activities, and provide individualized activities according to learners' different levels. In brief, learners' needs and levels of learning should be taken into account in order for them to be provided with suitable activities.

One of the strategies to realize "familiarity" is to familiarize learners with new knowledge through showing them the relationship between the new knowledge and their existing knowledge and skills. Besides, learners would feel relevant when the contents to be learned are related to their own experience, interest, values, ideals, etc.

\subsubsection{Confidence}

Confidence is very important as learners would keep on learning with the confidence of accomplishing tasks successfully. Confidence decides motivation to a great extent according to Victor H. Vroom's Motive Expectancy Theory: 
$\mathrm{M}=\mathrm{V} * \mathrm{E}$ ( $\mathrm{M}$ : motive force, $\mathrm{V}$ : value, $\mathrm{E}$ : expectancy). Confidence is proportionate to expectancy of success. In other words, there's low or even no expectancy when people have no confidence. Hence, when people have no confidence $(\mathrm{E} \rightarrow 0)$, they have no motivation to learn $(\mathrm{M}=0)$ even if they think learning can bring him enormous value $(\mathrm{V} \rightarrow \infty)$.

Keller views learning requirements, success opportunities and personal control as three factors affecting confidence [6].

1) Learning Requirements

Learners would have high expectancy to succeed after being told about requirements and evaluative criteria. They should also be encouraged to evaluate themselves positively with definite evaluative criteria, through which learners can be more confident when they live up to their own expectations.

2) Success Opportunities

Learners would be more likely to succeed in activities that are on the suitable level of difficulty. It should be stressed that suitable activities or tasks refer to those that can be accomplished with the help of teachers so that learners can be greatly motivated after accomplishing these tasks.

3) Personal Control

One important aspect of personal control is appropriate attribution. Helping excellent learners to attribute success to efforts will motivate them to work harder. Assisting underachieved learners to attribute failure to efforts rather than ability will not make them lose confidence easily. Another important aspect is suitable feedback. Providing suitable feedback can not only enable learners to face up to mistakes, but also allow them to know the reasons why they made mistakes.

\subsubsection{Satisfaction}

Satisfaction can contribute to sustained motivation. Learners would be satisfied and motivated when they obtain the positive results they expected.

1) Natural Consequences

Learners should be allowed to use newly acquired knowledge and skills in real situations. When they apply the knowledge which is relevant to them to authentic situations successfully, it is very likely for them to be inspired again.

2) Positive Consequences

Good behavior needs reinforcing so that it can be maintained. When learners perform well, teachers should provide positive feedback in the form of verbal praise, prizes, or caring attitudes, etc. And their intrinsic motivation could be stimulated after experiencing pleasure in the learning process.

3) Equity

Equity means the evaluative criteria are equal and open to everyone. If a learner finds that others receive better evaluation because of inequity, he or she would not be satisfied. Hence, equity is the premise for their taking part in activities.

The aforementioned four elements integrate with one another to form the ARCS model. According to Keller, the process of arousing learners' motivation can be summarized as five steps [15]. The first step is to collect course information and learners' information. The second step is to analyze this information in detail, which can help teachers to know the learners' situation in order for them to come up with individualized approaches to motivating them. The third step is to set motivational design goals. After that, the fourth step is to design methods to motivate learners and integrate these methods into the teaching process to form a specific plan. Finally, learners should be evaluated and encouraged to self-evaluate properly.

\section{The Stratified Teaching Method}

\subsection{Background to the Stratified Teaching Method}

Generally speaking, development of the stratified teaching method (hereafter "STM") can be divided into five stages.

The first one is the beginning stage. The Flexible Schedule proposed by W. T. Harris in 1868 is the prototype of stratified teaching, which classifies students into different levels according to their respective abilities.

The second is the stage of initial development. In the late $19^{\text {th }}$ and early $20^{\text {th }}$ century, the United States and Germany began to promote stratified teaching in order to better educate a large number of immigrant children whose knowledge and cultural backgrounds diversified. The U.S. government decided to teach students based on their grades and abilities. During this period, the STM developed into various forms, such as inter-school stratification, intra-school stratification, inter-class stratification, etc.

The third is the declining stage. From 1930s to 1945, global economic crisis, WWII and the public's belief that stratified teaching would lead to educational inequity led to the decline of this method.

The fourth is the recovery stage. To succeed in the technological revolution, many countries had a sense of urgency to cultivate "top students" after WWII. Various countries adopted STM again based on students' abilities and extended this form of teaching to secondary schools. During this period, subject-stratified teaching appeared.

The last stage is the flourishing stage. From 1960s to 1970s, many countries began to do research on stratified teaching. The development and appearance of new technologies and related teaching theories, such as Babanski's Optimization Theory, Zangkov's General Development Theory, Brumm's Mastery Learning Theory, Rodgers's Humanistic Education Theory, etc., facilitated the development of STM.

\subsection{Analysis of the Stratified Teaching Method}

Stratified teaching can be divided into two types: inter-class stratification and intra-class stratification. It requires teachers to set different teaching objectives and create different teaching situations for learners at different learning levels so that all the learners can achieve optimal development. The purposes of stratified teaching are: 1) to help every learner to set their own goals and realize their potential; and 2) to design individualized teaching activities according to learners' individual differences so that they can harvest confidence and satisfaction after accomplishing 
activities successfully.

The intra-class stratified teaching can also be divided into two types: explicit stratified teaching and implicit one. The latter does not necessitate breaking the structure of the class and the results of stratification are not announced, which is studied in this paper. Specifically, the author divides students into three levels: Level A (excellent students), Level B (average students), and Level C (underachievers). Then, the author designs a reading class according to students' individual differences, such as English proficiency, existing knowledge, learning attitudes and motivation, characteristics, etc.

\section{Necessity of Integrating the ARCS Model and Stratified Teaching Method into English Reading Classes}

\subsection{Importance of Reading}

Reading is one of the key teaching points in elementary schools in China. It is not only a platform for students to acquire language knowledge, but also a way to cultivate students' autonomous learning abilities. Meanwhile, reading abilities will also affect other basic language skills, i.e. listening, speaking and writing skills. Furthermore, students can broaden their channels of acquiring knowledge through reading.

\subsection{Reading and Motivation}

Motivation and emotions are two important factors, among others, that would affect students' reading abilities. Having high learning motivation is the first step to promoting students' active learning, and it can also help students to remove obstacles in the learning process to move forward.

Students in the fifth grade in elementary schools in China begin to learn texts and long dialogues. The increase in new words and the emergence of long sentences make them difficult for students to read and understand. In turn, reading difficulties would reduce their confidence in reading and hence lower their motivation to read. Therefore, it is of high necessity to stimulate students' English learning motivation.

As a representative of the teaching methods that emphasize students' individual differences, STM can not only effectively improve students' English reading abilities, but also improve their motivation in learning English.

However, most of the studies on stratified teaching focus on its theoretical framework, and there is no specific guidance for teaching design in reading class. The four elements of the ARCS model can well be combined with STM to design an effective English reading lesson. Besides, the specific methods of implementation proposed by Professor John Keller and others can also guide teachers in the process of instructional design, from understanding students and textbooks to evaluation after implementation.

\section{Application of the ARCS Model Based on the Stratified Teaching Method}

\subsection{Analysis of the Course}

\subsubsection{General Contents}

The English textbooks in use in elementary schools in Jiangsu, China are published by Yilin Press, which mainly include texts and dialogues about culture, education, life, science and technology. As regards those about culture, the themes are diverse, including festivals, languages, literature, scenic spots, tourist attractions, lifestyles, customs and etiquette, local customs and practices, etc. The textbooks are close to students' real life with illustrations and vivid images. In Book One of the fifth grade, there is one text about a western festival -- At Christmas, one text about a classical fairy tale -- Goldilocks and the Three Bears, one text about education -- Hobbies, and three texts about life -- A New Student, Our Animal Friends: What do they do?, and My E-friend.

\subsubsection{Advantages and Drawbacks}

One of the advantages of the textbooks is that their contents are not only rich and interesting but also connected to students' real life. Another advantage is that there is a self-evaluation section in every unit, which can serve as a guide for students to find and analyze their own inadequacies after learning every unit so that they can actively reflect on and possibly adjust their learning strategies. More importantly, their confidence and motivation in learning can be enhanced after getting positive evaluation. However, the self-evaluation section is not reliable and valid enough in that the exercises designed in this section are not so diversified. Furthermore, no questions or activities are designed before the texts.

\subsubsection{Suggestions for Improvement}

Based on the analysis above, it is suggested that teachers design some specific questions and/or activities according to the contents of every unit to lead in the lesson. Teachers are also advised to select some optional contents, which is consistent with the idea about students' stratification of learning. The self-evaluation part in each unit can be designed more specifically. For example, it can be designed after each class rather than at the end of every unit and the realization of individual goals can be part of the evaluation. What's more, the methods of evaluation can be more diverse. For example, individual evaluation, mutual evaluation, and teacher evaluation can be integrated with one another.

\subsection{Analysis of the Learners}

\subsubsection{Features of Attention}

The attention span of children aged 10 to 12 is about 25 minutes. To find out the features of attention of pupils in this study, i.e. students in two classes of the fifth grade in an elementary school in Taizhou City, Jiangsu Province, a survey was conducted. The results showed that $17 \%$ of the students only focus on the beginning of the class; $24 \%$ only pay 
attention to contents they are interested in; $47 \%$ feel that their attention is not so bad; and nearly $12 \%$ of the students say they can maintain their attention throughout the class.

\subsubsection{Features of Thinking}

Students in the fifth grade in elementary schools in Jiangsu Province are all 11 or 12 years old. Children at this age would be able to think logically with the help of concrete things or the images of them. Therefore, perceptual materials could be used to vividly display the teaching contents in teaching reading.

\subsection{Analysis of a Questionnaire}

In this study, 94 students in the two classes were surveyed in terms of their learning motivation, interest in learning materials and habits of learning. Ninety-four copies of the questionnaire were handed out and ninety-four were effectively recovered.

\subsubsection{Learning Motivation}

There are thirteen items on the questionnaire to gauge students' motivation in English learning, and for each item, there are four options below each statement: totally agree, agree, disagree, and totally disagree. Here, the author chooses several items for analysis.

1) I like learning English.

Table 1. Degree of liking towards English learning.

\begin{tabular}{llll}
\hline toally agree & agree & disagree & totally disagree \\
\hline $56 \%$ & $31 \%$ & $10 \%$ & $3 \%$ \\
\hline
\end{tabular}

It can be seen that most students (87\%) like learning English. As pupils have a strong thirst for knowledge and a curiosity for novelty, English, which is different from their mother tongue, often arouses their interest.

2) I learn English for my interest in this language.

Table 2. Intrinsic motivation for English learning (1).

\begin{tabular}{llll}
\hline totally agree & agree & disagree & totally disagree \\
\hline $18 \%$ & $31 \%$ & $39 \%$ & $12 \%$ \\
\hline
\end{tabular}

For this item, slightly less than half of the students (49\%) like English because of their interest in the language, which is a kind of intrinsic motivation. The rest of the students are driven by some kind of external motivation in their English learning.

3) I will learn English actively without teachers' or parents' supervision.

Table 3. Intrinsic motivation for English learning (2).

\begin{tabular}{llll}
\hline totally agree & agree & disagree & totally disagree \\
\hline $20 \%$ & $26 \%$ & $41 \%$ & $13 \%$ \\
\hline
\end{tabular}

It can be seen that less than half of the students (46\%) will learn English actively without teachers' or parents' supervision. It seems that it is quite necessary to develop the students' motivation to learn, especially intrinsic motivation, which can maintain their learning behavior for a long time.
4) I learn English in order to achieve good grades so that my classmates will admire me.

Table 4. Extrinsic motivation for English learning (1).

\begin{tabular}{llll}
\hline totally agree & agree & disagree & totally disagree \\
\hline $26 \%$ & $38 \%$ & $24 \%$ & $12 \%$ \\
\hline
\end{tabular}

5) I learn English in order to get awards and praise from my parents and teachers.

Table 5. Extrinsic motivation for English learning (2).

\begin{tabular}{llll}
\hline totally agree & agree & disagree & totally disagree \\
\hline $38 \%$ & $43 \%$ & $13 \%$ & $6 \%$ \\
\hline
\end{tabular}

Nearly two thirds of the students (64\%) learn English because they want admiration from their classmates and four fifths $(81 \%)$ praise and awards from their parents and teachers. This could be explained by the fact that affinitive drive, which is a kind of extrinsic motivation, affects their learning behavior enormously at their age. Therefore, teachers should give priority to intrinsic motivation and integrate it with external motivation to promote students' English learning.

6) I have confidence in learning English well.

Table 6. Confidence in English learning.

\begin{tabular}{llll}
\hline totally agree & agree & disagree & totally disagree \\
\hline $17 \%$ & $36 \%$ & $37 \%$ & $10 \%$ \\
\hline
\end{tabular}

It can be seen that slightly more than half of the students (53\%) are confident in learning English well, but the rest of the students lack confidence. As noted below, most students (89\%) agree that they can achieve confidence after answering teachers' questions correctly in class or accomplishing homework after class. Hence, teachers can motivate students to learn through asking some targeted questions or assigning proper homework according to students' individual differences.

7) My confidence will be strengthened after answering teachers' questions correctly, accomplishing tasks successfully or accomplishing homework.

Table 7. Performances in and outside class as an influencing factor of confidence.

\begin{tabular}{llll}
\hline totally agree & agree & disagree & totally disagree \\
\hline $46 \%$ & $43 \%$ & $6 \%$ & $5 \%$ \\
\hline
\end{tabular}

For this item, most students $(89 \%)$ replied that they would harvest greater confidence after answering teachers' questions correctly, or accomplishing tasks successfully in class, or accomplishing homework after class. It is thus very important for teachers to pay attention to questioning, organizing activities and assigning homework for their importance in improving students' confidence.

\subsubsection{Interest in Learning Materials}

The following two items measure students' interest in the learning materials in the textbook.

1) What do you think of the texts in the sections of "Story Time" and "Cartoon Time"? 
Table 8. Interest in the texts.

\begin{tabular}{lll}
\hline like & not bad & dislike \\
\hline $45 \%$ & $44 \%$ & $11 \%$ \\
\hline
\end{tabular}

The results show that $45 \%$ of the students like the texts while many students do not like them so much.

2) In reading class, what is your most expected topic?

The results (see Table 9 below) show that quite a lot of students (42\%) prefer topics about music, cartoon and movies, so teachers should actively use multi-media teaching facilities in the reading class. In addition, teachers need to communicate with students more to know more about their hobbies and specialities.

Table 9. Respondents' favorite topic in reading class.

\begin{tabular}{lll}
\hline $\begin{array}{l}\text { about music, } \\
\text { cartoon, movies }\end{array}$ & $\begin{array}{l}\text { about your own hobbies } \\
\text { and specialities }\end{array}$ & $\begin{array}{l}\text { about things happening } \\
\text { around you }\end{array}$ \\
\hline $42 \%$ & $32 \%$ & $26 \%$ \\
\hline
\end{tabular}

\subsubsection{Habits of Learning}

The three items below are designed to probe into students' habits of learning English.

1) Will you take notes in English classes?

Table 10. Note-taking habits in class.

\begin{tabular}{lll}
\hline take notes purposefully & sometimes & $\begin{array}{l}\text { only take notes when } \\
\text { asked by the teacher }\end{array}$ \\
\hline $13 \%$ & $18 \%$ & $69 \%$ \\
\hline
\end{tabular}

It can be seen that most students do not take notes purposefully in class, which probably reflect their lack of initiative in learning caused by insufficient motivation.

2) Will you read extracurricular English texts?

Table 11. Reading habits after class.

\begin{tabular}{llll}
\hline always & often & sometimes & never \\
\hline $6 \%$ & $19 \%$ & $50 \%$ & $25 \%$ \\
\hline
\end{tabular}

It can be seen that only a quarter of the students read extracurricular English texts on a regular basis. Considering their young age, it is difficult for them to read English texts after class with limited knowledge and vocabulary, but motivation in learning English can help them overcome difficulties to form a habit of reading.

3) How would you do the homework assigned by the teacher?

Table 12. Ways of doing homework.

\begin{tabular}{llll}
\hline $\begin{array}{l}\text { do the assigned } \\
\text { homework } \\
\text { independently }\end{array}$ & $\begin{array}{l}\text { do more homework } \\
\text { than assigned to } \\
\text { improve English }\end{array}$ & $\begin{array}{l}\text { do the easier } \\
\text { part of } \\
\text { homework }\end{array}$ & $\begin{array}{l}\text { copy } \\
\text { others } \\
\text { homework }\end{array}$ \\
\hline $63 \%$ & $16 \%$ & $11 \%$ & $10 \%$ \\
\hline
\end{tabular}

The results show that $63 \%$ of the students accomplish their homework independently, $16 \%$ of them do more homework than assigned to improve their English, 11\% only do the easier part and $10 \%$ copy others' homework. It can be seen that the homework assigned by the teacher is not suitable for all of the students and that assigning appropriate and individualized homework is significant as successful homework accomplishment can enhance students' confidence.

Based on the results of the survey and students' English proficiency, 47 students from one of the classes are divided into three levels, i.e. Level A, B and C (where A stands for top students, $\mathrm{B}$ for average students, and $\mathrm{C}$ underachievers). There are 15 students in Level A, 24 in Level B and 8 in Level C. To verify whether this classification is reasonable, these students are asked the following question: If you are to be grouped into different levels according to your English proficiency (A, B, C), which level do you think you should be grouped into? The results show that 14 students think they should be grouped into Level A, 24 students Level B, and 9 students Level C. It can be found that the students' own stratification is basically consistent with the author's.

\subsection{Analysis of the Interviews}

In this study, six students were selected randomly from the three levels (Level A, B, and C) for an interview about their learning motivation and behaviour. Three fifth-grade English teachers were also interviewed to find out their implementation of stratified teaching and the students' English learning motivation.

\subsubsection{Interview with Students}

Student Xie (Level A) says she learns English because of her love of the language. Her scores on English tests have been excellent and stable. She has strong motivation and behaves actively in class. She has a good habit of learning English, and asks questions, reads, listens and practices pronunciation every day.

Student Gu (Level A) says that her purpose of learning English is to get praise from her parents. Her approach to learning English is to do lots of exercises.

Student Wu (Level B) does not like English very much and only listens to the interesting part of the lesson.

Student Shen (Level B) is an average student who used to have bad scores on English tests. He says he often feel frustrated with his scores on these tests.

Student Yao (Level C) is poor in English. He says he is unwilling to recite texts and unable to concentrate in class.

Student Wang (Level C) says he dislikes English and needs supervision from teachers and parents to learn.

\subsubsection{Interview with Teachers}

A teacher surnamed Yin says that only top students have strong motivation to learn. She often asks the excellent students difficult questions.

A teacher surnamed $\mathrm{Ni}$ says that students' learning motivation is not very strong, and she would ask questions according to the students' different English abilities.

Another teacher surnamed You believes that students' learning motivation is not strong enough, and only one third of them are active in class. She also teaches based on her students' abilities. 


\subsection{Integrating Motivational Strategies with Reading Teaching}

\subsubsection{Attention (Lead-in, Pre-reading)}

The strategies to be used to grab students' attention in lead-in and pre-reading include the following: 1) using novel and popular materials as well as interesting or unusual activities to draw the students' attention. (e.g. pictures or videos about cartoon characters, or lively songs); 2) asking students some questions based on their different levels about the above-motioned materials or activities to lead in the class.

\subsubsection{Relevance and Confidence (Pre-reading, While-reading)}

The strategies to realize relevance and confidence in pre-reading and while-reading include: 1) showing the learners the value and objectives of this text; 2) offering learners various activities, exercises, or questions based on their different levels, existing knowledge, interest, and experiences; and 3) providing suitable feedback based on their levels and attributing success or failure to efforts.

\subsubsection{Satisfaction (Post-reading)}

The strategies to realize satisfaction in post-reading include the following: 1) allowing students to apply new knowledge to new situations; 2) asking Level A or Level B students to demonstrate; and 3) treating all students fairly.

\subsubsection{Evaluation After Class}

The teacher is advised to make evaluative forms for students to self-evaluate, and evaluate mutually, and he/she might as well give students some positive evaluations.

\section{An Example of Applying the ARCS Model Based on the Stratified Teaching Method to Reading Class}

The author takes "Unit 4 Hobbies" in Book One of the fifth grade as an example in an attempt to illustrate the application of the ARCS model based on stratified teaching in elementary school English reading class.

Unit 4 Hobbies

Objectives:

1) Knowledge objectives:

A. Students can master the new words and phrases: hobby, dance, play the piano, watch films.

B. Students can know the main idea and specific information of the text.

C. Students can know the sentence pattern: - What do you like doing? - I like...

2) Ability objectives:

D. Students can read the text correctly.

E. Students can use the sentence patterns to talk about hobbies.

F. Students can make up dialogues and retell the text.

G. Students can apply the knowledge to new situations expertly.
3) Emotion objective:

H. Students are willing to share their hobbies with friends.

Table 13. Stratification of objectives for students at different levels.

\begin{tabular}{llll}
\hline Objectives & Level A & Level B & Level C \\
\hline Knowledge objectives & A, B, C & A, B, C & A, B, C \\
Ability objectives & D, E, F, G & D, E, F & D, E \\
Emotion objective & H & H & H \\
\hline
\end{tabular}

Step 1: Lead-in (Attention)

1. Draw and guess

Draw the Peppa Pig partly and ask students to guess what it is. (Peppa pig is especially welcomed by students so that their attention can be drawn easily.)

2. Ask and answer

Ask students what Peppa Pig likes doing. The teacher imitates Peppa's voice to ask a student in Level A firstly and then ask more students to answer. (Considering that the new sentence is difficult for most students, the student in Level A can demonstrate for others.)

3. Tell students about the things that Pepaa Pig likes doing by referring to her hobbies and lead in the new lesson Unit 4 Hobbies.

Step 2: Pre-reading (Attention, relevance)

1. Ask students to talk about their own hobbies in groups and invite some students in Level B and Level C to answer.

2. Tell students about objectives of this class and some of objectives that they have achieved.

Step 3: While-reading (Relevance, confidence)

1. Match the pictures

Show students a video about the text and ask them to match the appropriate pictures with phrases on the blackboard. (Ask one student in Level B and three students in Level $\mathrm{C}$ to complete it and praise them.)

2. Ask and answer

Ask them some questions about the text based on their hobbies and levels. (If he/she is interested in playing basketball, he/she will be willing to answer questions about Mike.)

3. Fill in the blanks

Names What does he/she like doing?

Mike He likes...

Liu Tao He likes...

Yang Ling She likes...

Su Hai \& Su Yang Su Hai likes... Su Yang likes...

Ask one student in Level A to fill the last blanks. (It's difficult for most students but suitable for excellent students.)

Ask two students in Level B to fill in Mike and Liu Tao's blanks.

Ask one student in Level C to fill in Yang Ling's blank.

4. Make up dialogues

Ask students in Level B to talk about five characters' hobbies and ask some students in Level A to use their imagination to add new sentences.

Step 4: Post-reading (Satisfaction, confidence)

1. Read the text

Firstly, ask all the students to read after the tape. Then ask 
them to read in groups and correct pronunciation with each other. Finally, encourage some students in Level $\mathrm{C}$ to read and praise them. (Let Level C students know that the teacher likes their voice in order to encourage them to speak English more.)

2. Retell the text

Ask students in Level A to retell the text and ask students in Level B to retell with the help of the teacher and give them positive feedback.

3. Do the interview

Arrange every four students in a group and ask students in Level A or Level B to be the group leader to interview group members and to report in front of the class. (Meet the students' needs in Level A by asking them to perform in front of the class and help students in Level B to report successfully to get satisfaction. Students in Level C also participate in the activity with the help of the classmates.)

4. Play a level-based game about TFBoys' hobbies (TFBoys are popular among students in this grade)

Number 1: Watch a video about TFBoys and use newly acquired words and phrases to fill in the blanks. (Level C)

Number 2: Use newly acquired sentences and phrases to make up dialogues to talk about their hobbies. (Level B)

Number 3: Use new knowledge to summarize TFBoys' hobbies. (Level A)

Step 5: Evaluation (Confidence, satisfaction)

Encourage them to self-evaluate and evaluate mutually.

Step 6: Homework

Level A: Draw a mind map, retell the text to his parents, and accomplish individualized exercises.

Level B: Retell the text and accomplish individualized exercises.

Level C: Read after the tape for three times and accomplish individualized exercises.

\section{Conclusion}

English reading class proves to be an important channel for students in elementary schools in China to acquire English language knowledge, and develop their independent and creative thinking. Therefore, the motivation to read both intensively in class and extensively after class has an important bearing on the development of students' reading abilities. However, it is found by the present study that more than half of the respondents lack intrinsic motivation in English learning, which probably explains their learning attitude and behavior in and outside the classroom. It is thus of high necessity that teachers in English reading classes implement the ARCS model of motivation to design motivationally enhanced instruction based on the Stratified Teaching Method so that all the students would benefit in different but meaningful ways from the teacher's instruction.

\section{References}

[1] Keller, J. M. The use of the ARCS model of motivation in teacher training. In K. E. Shaw (Ed.), Aspects of Educational Technology: Staff Development and Career Updating (Vol. 17) [C]. London: Kogan Page, 1984: 140-145.

[2] Keller, J. M. Motivational design and multimedia: Beyond the novelty effect [R]. Paper presented at the International Symposium on New Technologies of Instruction, December, 1996.

[3] Keller, J. M. Using the ARCS motivational process in computer-based instruction and distance education [J]. New Directions for Teaching and Learning, 1999, (78): 37-47.

[4] Dick, W., \& Carey, L. The Systematic Design of Instruction (4th ed.) [M]. New York, NY: Harper Collin, 1996.

[5] Keller, J. M. \& Suzuki, K. Learner motivation and E-learning design: A multinationally validated process [J]. Journal of Educational Media, 2004, 29 (3): 229-239.

[6] Namura, K. et al. How can teachers motivate their learners in the classroom?: An exploratory study based on the ARCS Model [J]. Language Education \& Technology, 2007, 44: 169-186.

[7] Ghbari, T. The effect of ARCS Motivational Model on Achievement Motivation and Academic Achievement of the tenth grade students [J]. New Educational Review, 2016, 43 (1): 68-77.

[8] Li, K. \& Keller, J. M. Use of the ARCS model in education: A literature review [J]. Computers \& Education, 2018, 122: 54-62.

[9] Liu, Y.-M. Multimedia network technology-assisted foreign language teaching and the ARCS Model of motivation [J]. Journal of Xi'an International Studies University, 2006 (2): 54-56.

[10] Chen, L.-C. Research on the localization of the American ARCS Model of motivation [J]. Shanghai Research on Education, 2009 (12): 65-66.

[11] Yu, Q.-L. \& Wang M.-Q. Latest researches on ARCS motivational design and its application in foreign language teaching [J]. Technology in Education, 2015 (5): 103-109.

[12] Lin, L. ARCS Motivation Model in College English Classroom [D] Shenyang: Liaoning Normal University, 2008.

[13] Shen, Y. Analysis on the integration of ARCS Motivation Model and spoken English teaching [J]. Journal of Heilongjiang College of Education, 2012 (3): 170-172.

[14] Keller, J. M. Development and use of the ARCS model of instructional design [J]. Journal of Instructional Development, 1987, 10 (3): 2-10.

[15] Keller, J. M. How to integrate learner motivation planning into lesson planning: The ARCS model approach [J]. Integrating Motivation, 2000 (1): 2-11. 